\title{
Pragmatics of Sports News Reports
}

\author{
Fareed H. Al-Hindawi ${ }^{1} \&$ Ramia Mirza ${ }^{2}$ \\ ${ }^{1}$ College of Education for Human Sciences, University of Babylon, Iraq \\ ${ }^{2}$ College of Science for Women, University of Baghdad, Iraq \\ Correspondence: Ramia Mirza, College of Science for Women, University of Baghdad, Iraq. E-mail: \\ ramia.mirza@gmail.com
}

Received: September 30, 2017 Accepted: October 30, 2017 Online Published: December 23, 2017

doi:10.5539/ijel.v8n2p244 URL: http://doi.org/10.5539/ijel.v8n2p244

\begin{abstract}
The paper aims to build the structure of sports news reports by bridging them to pragmatics hence coming up with their pragmatic structure. Accordingly, two pragmatic concepts (viz. cooperative principle and speech acts) are believed to be helpful in performing this task. Moreover, the notion of dialectical relevance, developed by Walton (1995), is utilized. This is done by pragmatically analyzing eight news reports of different sports (football, tennis, formula1, and golf, respectively) taken from the BBC sports official website. The analysis is carried out by means of an eclectic model developed by the study itself to serve this aim. This type of analysis is supported by a statistical analysis to quantitatively validate its findings. The two types of analysis basically show that there are no major differences between the games analyzed as to employing the various strategies compiling the aforementioned analytic tool.
\end{abstract}

Keywords: summary category, main events category, headline, lead

\section{Introduction}

\subsection{The Problem}

Simple as it might seem, the language of sports news reports does have a number of features shaping its distinctive "charisma". The unfolding of such features is the main concern of this paper.

To start with, sports news reports might be a sparse source of exhibiting linguistic stylistic variation. This is due to the kind of events they rest on, which allow no embellishment as done with other types (e.g., political). Yet, this does not connote poverty of the source; it just highlights the challenge of investigating such a type of data.

Hence, this research attempts to answer the following question: Do the various sorts of sports (that is, those selected for analysis) differ in their employment of the strategies configuring their pragmatic structure? To perform this task, the paper starts with defining the concept of news and unfolding its generic structure. Then, the pragmatic structure of sports news reports is constructed in a way that accords with the aim of this paper. Then, a model is developed to serve this aim. The workability of the model is tested by analyzing eight reports on different sports taken from the BBC sports official website.

\subsection{Literature Review}

\subsubsection{What Is News?}

Though common and simple it is, the concept of news is so kaleidoscopic that it cannot be easily defined. Such multiplicity is conspicuously demonstrated in the batch of characteristics cited below:

News is based on the 3 W's: women, wampum and wrongdoing.

When a dog bites a man that is not news because it happens so often. But if a man bites a dog, it's new.

Journalism largely consists of saying "Lord Jones is dead" to the people who never knew that lord Jones was alive. (Web source: 1)

Each of these properties sheds light on a different aspect of news: core, surprise, and manipulation respectively.

Thus, defining this notion moves on a different path from what is traditionally known about defining any concept. This paper invokes Bell's (1991, p. 3) approach and the characteristics cited in web source 1 to draw news proper in general and identify sports news in particular, as they are the data under scrutiny. 
According to Bell (ibid.), news is made up of: hard news, features articles, special topic news and headlines. He details each component as follows:

1). Hard news: e.g., accidents, crimes, announcements

2). Feature articles: also called soft news, whose boundaries with the hard peer is usually fuzzy.

3). Special-topic news: e.g., sports, racing, arts, computers.

4). Headlines: crossheads, or subheadings: byline, photo captions.

The Public Affairs Qualification (cited in web source 1), in their turn, define news by means of its characteristics which the call "The Big Five": consequence, interest, timeliness, proximity, and prominence. Each is briefed below:

1). Consequence: Its main task is to inform and educate moral and/or social lessons_-it provides "should know" information. An example is: the political situation in Iraq,

2). Interest: As the name shows, it rests upon unusualness, entertainment and emotion-arouse that people talk about it. Examples are: conjoined twins undergoing surgery to be separated, the death of Margret Thatcher or a water skiing squirrel.

3). Timeliness: It has to do with trendy news or news of the moment, e.g., A tax story regarding a change in tax law.

4). Proximity: It refers to domestic issues, trends or events, e.g., A family losing a loved one in the battle of liberating Mosul.

5). Prominence: This pertains to well-known people and/or events or stories that grab media attention, e.g., Bill Gate's wealth.

Mixing these two opinions together helps the present work define sports news as: Special-topic pieces of information whose main characteristic is interest, especially entertainment.

Owing to the point that the main concern of this paper is sports news reports, it seems self-evident to give a brief idea about a news report. Agu $(2015$, p. 22) defines a news report as a provider of "details of a news story [whose purpose is] to give the reader or listener information in an interesting but objective way".

Rudiments of a News Story

Sunday et al. (2012, pp. 35-37) list the following principles for any news story, which are at the same time deemed a yardstick against which the value of news is measured:

1). Accuracy: This is a quality-based principle. It has to do with the precision of presenting data in news.

2). Attribution: This means source-ascription, whereby the story is attributed to a source. Attribution, however, does not guarantee the truth of the news presented; the onus of truthfulness is placed wholly with the source per se.

3). Balance and Fairness: This hinges upon impartiality whereby the different parties in news are treated equally and justly with no bias to occur.

4). Brevity: This is concerned with the amount of writing-less words, more meaning. It is preferable here to stick to the subject-verb-object structure, avoiding both adverbs and adjectives.

5). Clarity: This means the obviousness of writing by means of using words which communicate the required meaning without much processing.

6). Human Interest: This involves embracing elements of interest within the story, so that it could attract the reader's (or hearer's) attention. Such things as people, their reactions, expectations and their concerns are subsumed under this heading.

7). Identification: This has to do with pinpointing the people being talked about. The standard identification format is to mention the: name, age, address and occupation.

8). News point: This is concerned with the main theme the story; it provides the "backbone" of the whole story.

9). Objectivity: This means impersonalizing what is written: the unbiased aspect of the writer wherein any personal opinion is excluded.

10). Verification: Here, there is a process of checking information against some source: "it is recognition of the need for truth" (ibid., p. 37). This principle bolsters that of accuracy. According to Sunday et al., accuracy is not 
sufficient: a fact without truth is futile and false.

11). Completeness: This has to do with providing complete information which readers, viewers or listeners might ask the reporter about.

12). Responsibility: This is the pillar on which all the other principles rest. It shows a reporter's commitment to: story, journalism, and public. Sunday et al. (ibid.) think that "Responsibility demands of the reporter that the story be accurate, complete, fair and balanced, that it be so clear anyone can understand it" [sic!].

\section{Structure of News}

To understand the structure of news vividly, the structure of news in general is illustrated (that is, sports news has not been referred to yet). This "generic" structure is set by Van Dijk (1988), who uses the term "news scheme" throughout his work to cover all types of news. The present study, however, utilizes this structure in a way that serves its aims to develop its own structure with reference to sports news reports. Each of the structures is tackled in detail below:

\section{Van Dijk’s (1988) News Schema}

Van Dijk (ibid, pp. 52-56) depicts the structure of news by means of the following hierarchically ordered schematic categories:

Generally speaking, a news report consists of two main divisions under which all other categories are subsumed: Summary and Story. The former dominates: Headline and Lead where both summarize the news item. The latter, in turn, is subdivided into: Situation and Comments.

1). "Situation" is further subdivided into Episode and Background. The Episode consists of Main Events and Consequences. As its name shows, the Main Events (ME) category is built on the event which triggers the news (episode). Consequences, thus, has a judge-like action whereby part of the newsworthiness of social and political events relies on the seriousness of their consequences. The Background, however, covers: Context, History, and Previous Events. By Context is meant the information which creates the context of the main event. It is usually signaled by such conjunctions as "while, during", or similar expressions of simultaneity. As far as History is concerned, it is that category where past situations and their events are handled. Previous Events, on their part, are used as reminders of what has taken place before.

2). "Comments" includes Verbal Reactions and Conclusions. The former have to do with the comments of important participants or prominent political leaders. They are symbolized by "names and roles of news participants and by direct or indirect quotes of verbal utterances" (ibid., p. 56). The latter, then, are concerned with the comments, opinions and evaluations of the journalist or newspaper per se. It is further subcategorized into: Evaluations and Expectations. Evaluations supply the evaluation, that is, evaluative opinion, about the actual news event. Expectations, in turn, configure possible political or other predictions of the consequences of the actual event or situation.

Van Dijk (ibid.) stresses the point that not all these categories are equally important. Only the Summary Category and the Main Events Category are mandatory (hence, the most important); others are optional and/or recursive (thus, less important). This sets the rationale for selecting only the two mandatory categories as a basis for building the model in this paper. Figure (1), below, schematically shows the aforementioned structure.

Pajunen (2008, p. 3) believes that the salient feature of this structure is its being hierarchical: the most relevant (i.e., important) information comes first and less important pieces come late. That is why Pajunen (ibid.) resembles this generic structure to an inverted pyramid as shown in Figure (2):

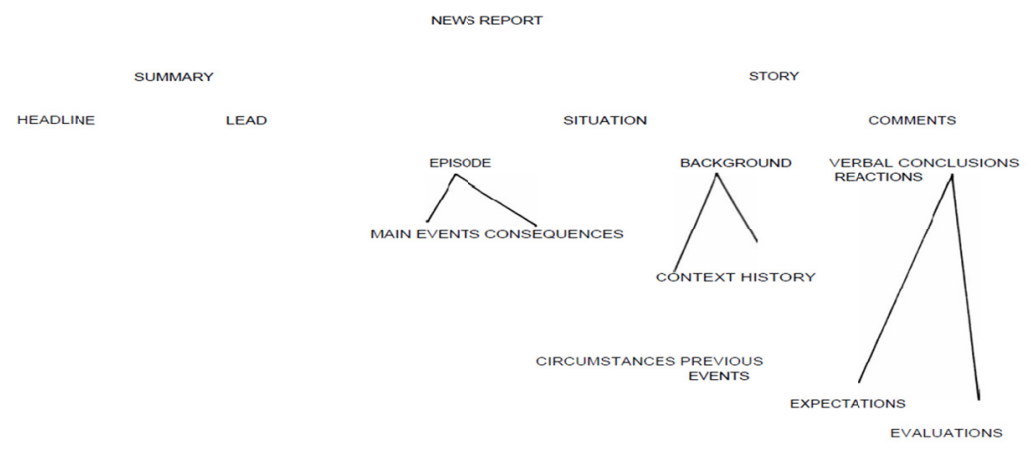

Figure 1. Hypothetical structure of a news schema (After Van Dijk, 1988, p. 55) 


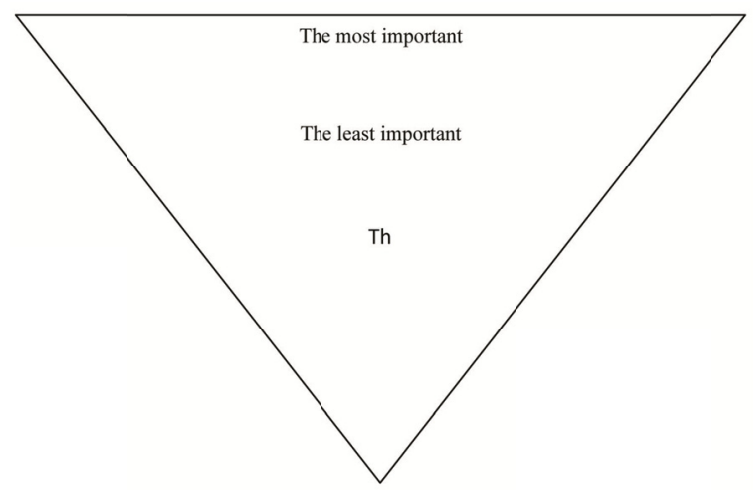

Figure 2. The Inverted pyramid model of a news story (After Pajunen, 2008, p. 3)

Owing to selecting the two mandatory categories only, each is tackled in detail in what serves the aim of this work.

\subsubsection{The Summary Category: Headline and Lead}

Both headlines and leads are part and parcel of a news story in which they show some feature in common: they provide "the most central, essential and relevant information". As well-known, a headline is shorter than the lead; as such it cannot give as much information as that found in the lead. This makes Bell (1991, p. 150) call the headline "abstract of the abstract". It can be restated, thus, that a headline is a mould which first shapes the reader's (or hearer's) mind as to what might come next. Such prediction is supported by what a viewer (reader or hearer) finds in the lead. Metaphorically speaking, the relationship between a headline and lead is just like a loupe wherein the frame represents the headline and the lens resembles the lead.

However, each of them has its own characteristics the illustration of which is in what follows:

\subsection{Headline}

This is a self-defining term which needs no explanation. Pajunen (2008, pp. 8-9) discusses headlines at two levels: syntactic and pragmatic (as titled in this paper). The first level is out of the concern of the present study and that is why it is not dealt with; the focus, hence, is on the second level. There are two types of headlines, Pajunen (ibid.) argues: those pertaining to the main topic and others referring to a secondary topic. To elucidate his idea more, Pajunen invokes Mardh's 1980 distinction between a summary head and a connotative head. By the former is meant a neutral summary of the news story; the latter, in turn, sheds light on a specific aspect of the story.

\subsection{Lead}

This represents the paragraph which paves the way for the story as a whole. As mentioned earlier, news follows a top-down scale of importance in which the most relevant comes first. As such, the first paragraph beckons the lead in any news report. Within the lead itself, Bell (1991, p. 176) comments, "the most important information is put at the beginning, not at the end of the paragraph".

Once more, two levels of analysis are cited for this component: syntactic and pragmatic. The first, which is out of the scope of this work, is set in place by Van Dijk (1988). The second, by contrast, is delivered by Bell (ibid.) whereby three scales are proposed to evaluate the lead:
1). Brevity
2). Clarity
3). Newsworthiness (Cf. 3 above).

Pajunen (2008, p. 10) rephrases Bells opinion as follows: "leads should be full on information [sic!], yet as short as possible and easily comprehended".

\section{The Main Events Category}

This makes the core on which the whole story (or report) is built. Needless to mention that what matters in this paper is the linguistic facet, and that is mainly represented in this category by the employment of quotations and reported speech as revealed by the data under investigation. Consequently, these two are deemed the actual 
realization of the main events.

\subsection{Quotations and Reported Speech}

These are clear enough linguistic phenomena that have been dealt with extensively throughout the past years. Nevertheless, the way they are utilized in news is what our work is concerned with.

\section{Quotations}

The subtlety of quotations lies not in the quotation itself as it is in the selection per se. That is to say, quotations are the exact words used by a source on some topic; yet selecting a specific quotation does not necessarily pertain to the context created in the news, they might have been said in another context. Accordingly, the use of quotations has two valences: objective and subjective. The former resides in the exact words, the latter in the selection of those words (ibid., p. 13). There is a sub-category of quotes where single words, not complete clauses or sentences, are enclosed between quotation marks - scare quotes as named by Bell (1991, p. 208). Their effect is to question, disparage, undermine or be aware of what they enclose. Bell (ibid.) cites the following example:

Indian Prime Minister Vishwanath Pratap Singh accused Pakistan today of "evil designs" as tensions between the two countries rose after skirmishes along their disputed border in Kashmir.

\section{Reported Speech}

This refers to the process of reporting what others say by means of the reporter's own words not the source's. The reporter communicates what is said via a particular verb (i.e., reporting verb) which shapes what comes next, as believed by Pajunen (2008, p. 13). He (ibid.) lists the following reporting verbs distributing them on a continuum of neutrality and non-neutrality (which does not necessarily indicate bias, it just highlights some specific opinion):

1). Say, tell, and the non-finite form according to: These are neutral as far as the reporter's opinion is concerned.

2). Claim and agree: They should be used in the right context because they yield particular meaning which are context-sensitive.

3). Snap and smile: These are subjective reporting verbs, with the former pinpointing pejorative affections, and the latter positive counterpart.

\subsection{Hypothesis}

The study hypothesizes that the different kinds of sports (i.e., the data under scrutiny) differ in their employment of the various strategies which constitute their pragmatic structure. To verify or reject this hypothesis, the model developed by the study is used and then the obtained findings are handed over to statistical analysis by means of the percentage equation to quantitatively validate them.

\section{Method}

In order to objectively analyze the data of the work, a model is developed to serve this aim. Following is a detailed description of the pragmatic structure embracing the various strategies used to analyze sports news reports.

\subsection{Pragmatic Structure of News as Developed in This Paper (The Eclectic Model)}

After surveying the most relevant components of news as approached in this study, the pragmatic structure, intended to be developed here, is ready to be processed.

Van Dijk's (1988) generic structure is only partially adopted owing to the following:

1). It analyzes news as a piece of discourse at various levels: semantic, syntactic, pragmatic, stylistic and even rhetorical. Such an all-embracing treatment resembles very much the proverb "A jack of all trades is a master of none". His work cannot be described as semantic, syntactic, pragmatic, etc. This miscellaneous tackling is what distinguishes his work from ours which is purely pragmatic.

2). His work pertains to news in general with no reference to any particular type (thus the term generic). The trend in this work, by contrast, is mainly formulated for sports news reports.

Accordingly, the pragmatic structure of the aforementioned news is synthesized as follows: It consists of two major categories: Summary Category and Main Events Category. Each is re-modeled below:

\section{Summary Category}

As indicated above, this category hinges upon a headline and a lead. The headline is, also, of two types: 
summary (involving a neutral stand); and connotative in which pragmatics comes to the scene. However, since this study is mainly pragmatic, the neutral stand representing the summary type, then, is instantiated by the speech act of summarizing, for the sake of keeping to consistency.

Connotative meaning, Leech (1974, p. 14) defines, "is the communicative value an expression has by virtue of what it refers to, over and above its purely conceptual content". This definition is pragmatically mirrored in the concept of conversational implicature via which more is communicated than what is literally said. This entails equating connotation to the conversational implicature generated by violating one or more of the Gricean maxims.

As far as the lead is concerned, it is evaluated by the three scales indicated before: brevity, clarity, and newsworthiness. Interestingly, these scales also equate the Gricean maxims: quantity, quality (or manner) and relevance, respectively. This equation should not trigger the over-hasty conclusion that both elements are analyzed by means of those maxims; only the headline is analyzed as such. The lead, however, is analyzed by another principle: relevance. It is so because of the point previously highlighted that the most relevant information comes first in the lead. Moreover, Wilson \& Sperber (2004, p. 607) argue that "the expectations of relevance raised by an utterance are precise enough and predictable enough to guide the hearer towards the speaker's meaning". Nevertheless, by relevance is not intended the notion developed by Sperber and Wilson whereby relevance is dealt with at two levels: cognitive and communicative. Instead, the notion of dialectical relevance as developed by Walton (1995) is adopted. According to him (ibid., p. 163), "relevance of any argument or any of its parts is to be sought in understanding just how it or they contribute to the structure of the dialogue [report] as a whole". Dialectical, that is, purposeful, relevance is of two major types which Walton (1995 and 2006) calls topical and probative. By the first is meant "subject-matter overlap", as in Socrates is Greek. Plato is Greek (Walton, 1995, p. 171).

Probative relevance, on the other hand, is proposition or speech act-based. It is used to (dis)prove another proposition, as in: All Athenians are Greek and Socrates is Athenian. Socrates is Greek (Walton, 2006, p. 271).

This makes Walton's relevance show the relationship between the various components of a text. As such, the relationships between the lead and the headline, on one hand, and between them and the main events category, on the other, are revealed. It is necessary to state that relevance in the model diagram is numbered, in which relevance 1 refers to the relationship between the headline and lead, whereas relevance 2 belongs to that holding between the two main categories. Van Dijk $(1988$, p. 53) can help justify such a procedure: the headline and lead in tandem express the major topics of the text; hence the type of relevance maintained between them differs from that holding between the two main categories.

\section{Main Events Category}

The two subcategories here are quotations and reported speech. The first accepts no explanation as it represents the source's exact words. Only that special type of quotations - scare quotes - is analyzed, if any, as shown below. Analyzing the reported speech is what matters to this work.

As previously pointed out, reported speech has two parts: the reporting verb and the reported content. As regards the former, the most commonly used verbs are already listed by Pajunen (See above). However, if other verbs are used in the data, they will also be added to the analysis. Concerning the reported content, it is to be analyzed by invoking Mustafa (2010, p. 40) who defines news reporting as "process which includes acts of assert, state that, and affirm". Accordingly, analyzing the reported content is performed by means of speech acts which are mainly but not restrictively assert, state, and affirm. Still, an open node is left should any kind of speech act is discovered other than those already listed.

One last point to raise here is that since a scare quote does not enclose complete clauses or sentences, thus it occurs within reported speech. Whenever such a case arises, it is also analyzed by means of speech acts as the case with the reported content.

The following diagram schematically depicts the pragmatic structure of sports news reports as developed in this paper whereby the arrow maintains two references:

1). The component part of some element; and

2). The relationship between one category and another

The double bracket, in its turn, encloses a category. 


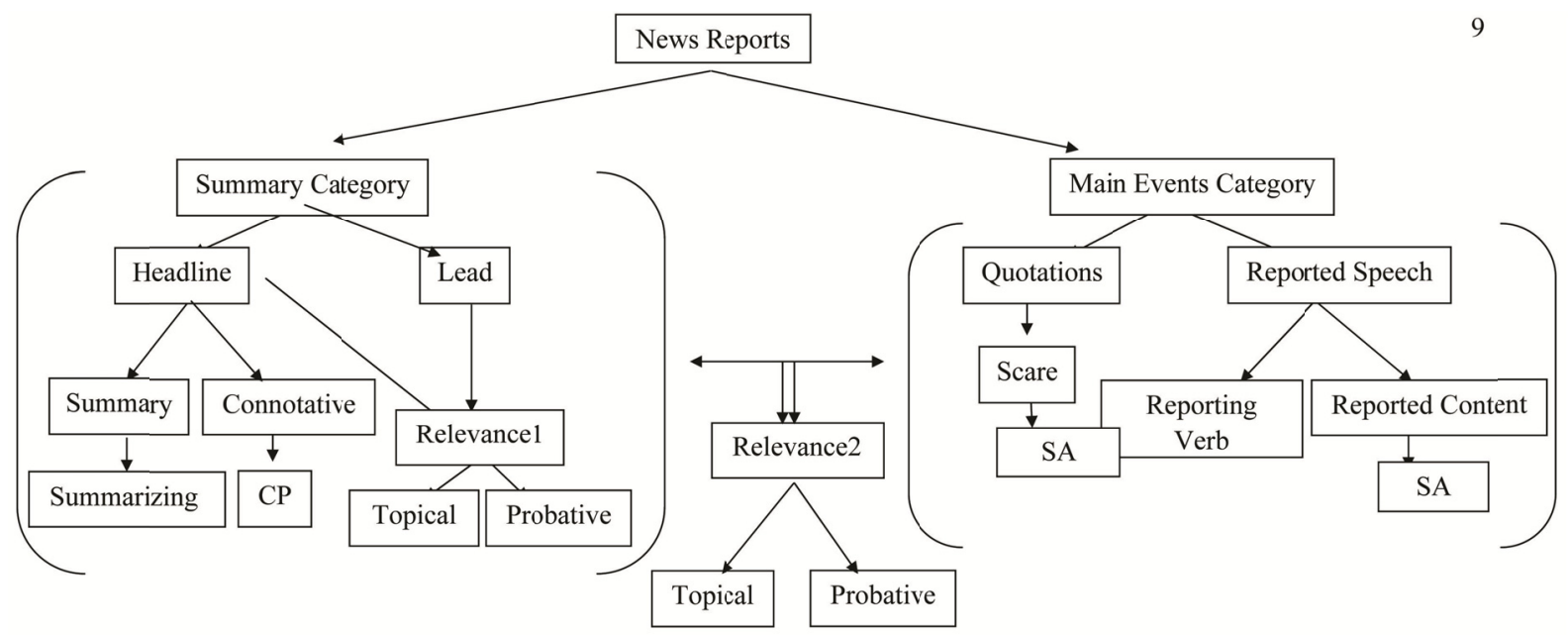

Figure 3. The pragmatic structure of (sports) news reports

Note. CP: Cooperative Principle, SA: Speech Act, V: Verb.

\subsection{Data Analysis}

In this section, the purely pragmatic aspect of sports news reports is empirically demonstrated. This is performed by:

1). Utilizing the eclectic model as developed in this paper;

2). Using the percentage equation as the basis of the statistical comparison maintained between the obtained results.

The data of the study are selected from the BBC sports official website (Web source 2). Four categories of sports are dealt with: football, tennis, golf, and formula 1. These categories are selected, out of the eight mentioned in the website, owing to:

1). Their popularity;

2). The fact that the data are too many and analyzing all of them is time and space consuming. The data selected, however, are representative and rich enough to shed light on the workability of the model and showing the kind of analysis conducted.

It is worth mentioning that two examples of each of these categories are given. This is done for the sake of bolstering representativeness of the data. Nevertheless, one example on football is analyzed first, then one for tennis, another one for golf, and the last one for formula 1. The remaining examples are listed on a table following the analysis; the results of all the data are statistically calculated.

\subsubsection{Pragmatic Analysis}

Following is the pragmatic analysis engendered by analyzing examples on football, tennis, formula 1, and golf, respectively. The relevant data to the analysis, as imposed by the developed model, are italicized for the sake of more clarification. However, the headline is highlighted by being bold and italicized; the lead by being underlined.

\section{Football}

Espen Nystuen at Kongsvinger: The player who can hire and fire managers

We have all heard about player power at certain clubs, where influential players expect a say in whether the manager stays or goes, or who replaces him.

Well, Norwegian club Kongsvinger has taken it to another level.

Veteran centre-back Espen Nystuen, 34, literally did pick the club's manager and has the power to sack him whenever he wants. In 2013, he returned to his hometown club - but not in a standard role. Nystuen, who had been playing for Lillestrom in the top flight, arrived as the club's managing director — and is a regular at the heart of their defence.

And it is obviously working. Since recruiting little-known Portuguese manager Luis Berkemeier Pimenta, who 
has a degree from Liverpool John Moores University, in 2014, the club have won promotion from the third tier and are in the play-offs this season bidding to return to the top flight.

But before that, they face the biggest game in their history.

On Sunday, the second-tier side play in their first Norwegian Cup final - against the country's most successful team, Rosenborg.

"T have quite a special role in Kongsvinger," Nystuen told the BBC World Football Show. "Luis is my boss on the pitch - and off the pitch, I'm the one taking the decisions.

'I'm definitely on my way down as a player. When I'm out on the pitch, I act like I've always done, no matter what coach I have had. It's of course him who makes the decisions. In the office, we have managed to create a good atmosphere. For me, in the role as director, it's much more calm. On the pitch it's more feelings, emotions

Despite their success, the pair do have their disagreements over team selection-although the dispute is not over whether Nystuen, who can be as confident as a player can be of starting a cup final, plays.

When Nystuen was asked what happens if Pimenta drops him, he joked: "Then he's finished right away. He wouldn't dare do that".

Nystuen wants more youngsters in the first team. "The first-team coach of course has to think about what's best for the first team, while my role I also care about what happens to the second and junior teams.

"We don't agree all the time about giving those youngsters their best match level and development. Not only doing what's best for the next match but also thinking one and two years ahead. But it has worked quite well even though we have had our fair amount of discussions".

Could Kongsvinger write the greatest chapter in their 124-year history this weekend?

Nystuen, who wears the number 10 shirt, is a realist. "They are probably the biggest favourites who have ever been in the cup final in Norway," he said.

"They have a far better side than us but we have created a good atmosphere. If we are going to beat Rosenborg, which of course will be difficult, that is our biggest strength-we run more than them and work harder for each other than they do. If we manage to do it, it has to be in that way."

\section{Summary Category}

The headline is connotative because it communicates more than what is literally said, as such an implicature is generated. It is initiated by violating the relevance maxim: a player does not hire and/or fire managers. Thus, there is a reference to Nystuen's power over the team as a whole.

The lead, i.e., the underlined words above selected on the basis that it is the first paragraph in a news report ( $C f$. 4.2.1.1 above), is probatively related to the headline. This can be shown as follows:

The headline implies that Nystuen is an especially powerful player who can hire and fire mangers; the lead, in turn, also pinpoints the issue of power which Nystuen has, nevertheless, taken to another level. Hence, the main point in both categories (i.e., headline and lead) is Nystuen's special power.

\section{Main Events Category}

Owing to the fact that there might occur more than one quotation in the news, each quotation with its reporting verb is cited for the sake of clarity and accurate statistics.

"I have quite a special role in Kongsvinger," Nystuen told the BBC World Football Show. "Luis is my boss on the pitch - and off the pitch, I'm the one taking the decisions.

"I'm definitely on my way down as a player. When I'm out on the pitch, I act like I've always done, no matter what coach I have had. It's of course him who makes the decisions. In the office, we have managed to create a good atmosphere. For me, in the role as director, it's much more calm. On the pitch it's more feelings, emotions".

The reporter's opinion here is neutral due to the use of the "told" (The reported content, in turn, involves the following speech acts: statement and assertion.

When Nystuen was asked what happens if Pimenta drops him, he joked: "Then he's finished right away. He wouldn't dare do that".

The reporter's positive opinion is manifested by the use of the verb joke. The reported content, however, involves the speech act of assertion.

Nystuen wants more youngsters in the first team. "The first-team coach of course has to think about what's best 
for the first team, while my role I also care about what happens to the second and junior teams.

"We don't agree all the time about giving those youngsters their best match level and development. Not only doing what's best for the next match but also thinking one and two years ahead. But it has worked quite well even though we have had our fair amount of discussions".

What is remarkable about this quotation is its being free from any reporting verb. Moreover, the reported content does not communicate what is mentioned in the quotation. That is, Nystuen "cares about what happens to the second and junior teams", whereas the reporter claims "Nystuen wants more youngsters in the first team" which is inadequate because caring about something is not the same as wanting it. It follows that such kind of data does not lend itself for being analyzed by the developed model and hence its accuracy shows (i.e., the model's).

Nystuen, who wears the number 10 shirt, is a realist. "They are probably the biggest favourites who have ever been in the cup final in Norway," he said.

"They have a far better side than us but we have created a good atmosphere. If we are going to beat Rosenborg, which of course will be difficult, that is our biggest strength-we run more than them and work harder for each other than they do. If we manage to do it, it has to be in that way."

Again, the reporter here is neutral as he uses said. The reported content employs statement as its instantiating speech act.

The type of relevance maintained between the first and second categories is topical because the Nystuen's quotations invoked do not prove or disprove the first category; they just show his position and not how he can fire and/or hire mangers, which is the pillar of this news.

\section{Tennis}

Andy Murray claims place in Shanghai Masters final as Novak Djokovic loses

Andy Murray is through to the Shanghai Masters final and will play Roberto Bautista Agut, after Novak Djokovic smashed his racquet and tore his shirt as he lost to the Spaniard.

The world number one, 29, lost 6-4 6-4 to world number 19 Bautista Agut.

Murray reached his 10th final of the year with a determined 6-4 6-3 semi-final win over France's Gilles Simon.

The 29-year-old Briton, seeking his sixth title of the year, saw off world number 32 Simon in a confident display.

If Murray wins Sunday's final he will be just 915 points behind Djokovic in the annual rankings points, increasing his chances of finishing as the year-end world number one.

Having ripped his shirt open in frustration, Djokovic was further incensed at receiving a time violation when changing into a new one, raising the point forcefully with umpire Carlos Bernardes at the end of the match.

"He was the star of the show," Djokovic said of the official. "That's what he wanted to be today.

"But there are definitely things that I need to regain from the emotional, mental point of view."

Djokovic, who has won the event three times and was also aiming to reach his 10th final of the season, said exhaustion may have played a part in his mood during the match.

"I had to experience this sooner or later," he said. "I knew I could not go on playing at the highest level for so many years all the time."

The world number 19 took the first set against Djokovic in 42 minutes with his first break point and broke three times in the next to triumph in an hour and 47 minutes.

The Serb, who had won all five of his previous encounters with his opponent, could make little headway against Bautista Agut's intrepid, athletic baseline tactics.

Djokovic failed to take the two break-point chances he was able to create in the opening set and it was his opponent who seized the opportunity, prompting the 12-time Grand Slam title winner to smash his racquet beyond repair.

Djokovic had committed 37 unforced errors before beating world number 110 Mischa Zverev in the previous round, and was soon a point away from a 5-2 deficit in the second set against 15th seed Bautista Agut.

He held off three match points as the Spaniard's serve showed signs of tension, but made further mistakes when serving to level at 5-5-with 29 unforced errors in total during the contest—as Bautista Agut reached a Masters final for the first time. 
Murray has said that reaching the world number one spot is his main aim for the rest of the 2016 season.

However, speaking after his match with Simon, he accepted that Djokovic's exceptional start to the season has made that "difficult" for him.

"I said that I want to try to get to number one, but I'm still quite far away from [Djokovic], so I'm not thinking about the number one ranking this week or right now," he said.

"I just want to finish this year as best as I can, it's been the most successful in my career.

"The last few months have been some of the most consistent I have been, so I just want to keep it going until the end of the year and finish as strong as possible."

Novak Djokovic has experienced a strange sensation in recent months

Having not lost his serve throughout the tournament, Murray was broken in the very first game of the match, setting the tone for a compelling opening set.

After six successive breaks of serve Murray capitalised on a set point when, having been lobbed himself, he raced back and produced a sublime backhand lob of his own.

The first set took 53 minutes, but Murray clicked into a higher gear in the second, pulling away from the determined Simon.

The match seemed done and dusted when Murray was serving for a place in the final at 5-1, only for a combination of Simon's grit and the Scot's serving errors to keep both men on court.

That quickly became back-to-back games for Simon, leaving Murray under some pressure in his second attempt to serve out the match.

But the Scot thrives under such pressure, and sent down an ace to seal his place in yet another final.

\section{Summary Category}

The headline in this example is of the summary type, that is, it does not connote any extra meanings. This is supported by what is mentioned in the lead which summarizes what is previously stated in the headline. Thus, these two elements are probatively related.

\section{Main Events Category}

"He was the star of the show," Djokovic said of the official. "That's what he wanted to be today.

"But there are definitely things that I need to regain from the emotional, mental point of view."

The reporter is neutral in expressing his opinion here as the verb "said" is used. Besides, two speech acts are issued in this example: statement and assertion.

"I had to experience this sooner or later," he said. "I knew I could not go on playing at the highest level for so many years all the time."

Again, the reporter is neutral owing to the use of "said". What is more, affirmation is the speech act detected here.

"I said that I want to try to get to number one, but I'm still quite far away from [Djokovic], so I'm not thinking about the number one ranking this week or right now," he said.

"I just want to finish this year as best as I can, it's been the most successful in my career.

"The last few months have been some of the most consistent I have been, so I just want to keep it going until the end of the year and finish as strong as possible."

The neutral opinion is expressed by using the verb "said". Three statements are issued here as the speech acts invoked.

The type of relevance linking between the two categories is probative because everything mentioned in the report serves the point raised by the headline.

\section{Formula 1}

Lewis Hamilton: Mercedes will wait to decide on any action for ignoring team orders

Bottom of Form

Will Rosberg and Hamilton become best of friends, again?

Mercedes say there is "no rush" to decide whether to take further action against Lewis Hamilton following the 
season-ending Abu Dhabi Grand Prix.

Hamilton drove deliberately slowly in an attempt to back team-mate Nico Rosberg into rivals. The German finished second to win his first title.

"There's no time pressure," a spokesman said. "We'll let the whole thing settle and then figure out the way forward.

"For now, the focus is on savouring and celebrating the world championships."

Mercedes repeatedly ordered Hamilton to speed up during the race, telling him the win was under threat if he did not.

But he rejected their commands and told his team to "let us race".

Hamilton went into the race 12 points behind Rosberg and needed to win with the German finishing lower than third - to take the title.

- The season of Rosberg's life but "never Hamilton's equal"

- The "toughest race of my life"-Rosberg

- "Car failures cost me title"-Hamilton

- Does Rosberg deserve F1 title?

- Nigel Mansell: Hamilton's tactics caused great concern

Hamilton insisted after the race he had only lost the championship because he had had more technical failures on his car than Rosberg during the season.

Mercedes F1 boss Toto Wolff said: "We need to look at the overall situation and say "what does it mean?".

"Everything is possible - from "let's change the rules next year because it doesn't work in those critical races and maybe we want to give them even more freedom in racing each other", to the more harsh side that we feel the team's values were not respected.

Nico Rosberg: Is Mercedes driver a worthy F1 world champion?

"This is 180 degrees and I am not sure yet where the needle is going to go."

Wolff said he could understand Hamilton's actions on a personal level, but also that, as a man responsible for the racing operation of a global corporation, he might have a different view.

"I was in two minds," he said, adding the team values of Mercedes are "pretty clear" and "it cannot make a difference whether it was the first or last race".

"Those principles and values have won us races and championships and so this is one side.

Nico Rosberg tweeted a picture of himself and friends, including Red Bull driver Daniel Ricciardo, celebrating 2016 F1 title win.

"And the other side, me the racer, says maybe I would have done the same.

"He had two choices - disappear into the distance and show he is the quickest guy on the planet irrespective of what's happening in the back or decide the other way and bunch them up behind him.

"So we have to calm down. There is so much more going on in the background that plays a role in how we are thinking and this is why I don't want to express an opinion before I have actually made up my mind for myself."

Rosberg said: "I wasn't expecting it, no. Maybe that was a bit naive, but I didn't expect it.

"But it's not something I need to discuss because it is really easy to understand the team's side because we have done the same thing all year and it doesn't change in the last race, but at the same time you can understand Lewis.

"It's the world championship and we are out there fighting and you have to understand he wants to try something. We don't need to discuss it anymore."

\section{Summary Category}

Summary is the type of headline found in this example. It summarizes what is pointed out in the lead. As such, they are probatively related to each other. 


\section{Main Events Category}

"There's no time pressure," a spokesman said. "We'll let the whole thing settle and then figure out the way forward.

"For now, the focus is on savouring and celebrating the world championships."

The reporting verb used here is "said", thus the neutral point of view is recorded. Two speech acts are issued: promise and statement, respectively.

But he rejected their commands and told his team to "let us race".

The neutral report is expressed by "told". An example of scare quotation is presented here. It is instantiated by the speech act of invitation.

Mercedes F1 boss Toto Wolff said: "We need to look at the overall situation and say "what does it mean?"

"Everything is possible-from "let's change the rules next year because it doesn't work in those critical races and maybe we want to give them even more freedom in racing each other", to the more harsh side that we feel the team's values were not respected.

"This is 180 degrees and I am not sure yet where the needle is going to go."

A neutral viewpoint is communicated by using the verb "said". The speech act of statement is what is detected at this point.

"I was in two minds," he said, adding the team values of Mercedes are "pretty clear" and "it cannot make a difference whether it was the first or last race".

"Those principles and values have won us races and championships and so this is one side.

Two reporting verbs are used here - both are neutral: said and added. The speech act issued is statement.

Nico Rosberg tweeted a picture of himself and friends, including Red Bull driver Daniel Ricciardo, celebrating 2016 F1 title win.

"And the other side, me the racer, says maybe I would have done the same.

"He had two choices - disappear into the distance and show he is the quickest guy on the planet irrespective of what's happening in the back or decide the other way and bunch them up behind him.

"So we have to calm down. There is so much more going on in the background that plays a role in how we are thinking and this is why I don't want to express an opinion before I have actually made up my mind for myself."

The reporting verb used here is "tweeted". Three speech acts are invoked: affirmation, statement and justification, respectively.

Rosberg said: "I wasn't expecting it, no. Maybe that was a bit naive, but I didn't expect it.

"But it's not something I need to discuss because it is really easy to understand the team's side because we have done the same thing all year and it doesn't change in the last race, but at the same time you can understand Lewis.

"It's the world championship and we are out there fighting and you have to understand he wants to try something. We don't need to discuss it anymore."

The use of the verb "said" supports the neutral viewpoint of the reporter. Three speech acts are issued here: statement, affirmation, and statement, respectively.

The two categories are probatively related to each other, everything mentioned in second category is used to prove what is pointed out in the first.

\section{Golf}

Charley Hull wins the CME Group Tour Championship for first LPGA title

Bottom of Form

England's Charley Hull has won the CME Group Tour Championship by two shots to earn her first LPGA title.

The 20-year-old finished on a tournament record 19 under par to beat South Korea's Ryu So-yeon.

Hull startedz the final round with a one-shot lead ahead and shot six birdies in her bogey-free round for a six-under-par 66 at the Florida course.

"It's wicked to do it at 20," she said. "It feels good to be joining the winners this year." 
World number one Lydia Ko was tied for 10th, while England's Jodi Ewart Shadoff finished tied for 36th.

Scotland's Catriona Matthew finished in 46th place.

Hull had been tied with Ryu after 16, but the Korean missed her par putt on the 17th as Hull birdied the hole to take the lead and complete a two-shot swing.

Both players then are on a par as the last as Hull took the title, in the final tournament of the season.

The world number 29, who finished seventh at the Rio Olympics, had a bogey-free weekend, with 12 birdies and 24 pars in her final 36 holes and wins $\$ 500,000(£ 404,891)$ in prize money.

"I just feel pretty good where I am at the moment," added Hull. "I feel like I am mentally good. I feel relaxed. I think that's the key for me.

"If I come into a week relaxed I feel good. This week it happened for me. I'm confident. I'm happy."

It is Hull's second title since turning professional in 2013, having won the Lalla Meryem Cup on the Ladies European Tour in 2014.

\section{Summary Category}

The headline in this example is summary as it communicates no additional unsaid information; rather, it summarizes what is indicated in the headline. Accordingly, the type of relevance interwoven between the headline and the lead is probative. The latter is used to support the former.

\section{Main Events Category}

"It's wicked to do it at 20," she said. "It feels good to be joining the winners this year."

The reporter's neutral opinion is shown by using "said". one speech act is employed here: statement.

"I just feel pretty good where I am at the moment," added Hull. "I feel like I am mentally good. I feel relaxed. I think that's the key for me.

"If I come into a week relaxed I feel good. This week it happened for me. I'm confident. I'm happy."

Again, the neutral opinion is expressed by using "added". Moreover, the speech act of statement is used twice here.

The two categories are probatively related to each other. What is mentioned first paves the way for what is brought about later in the report.

Table 1. Analysis of the remaining examples

\begin{tabular}{|c|c|c|c|c|c|c|c|c|c|}
\hline \multirow[b]{4}{*}{ Type } & \multirow{2}{*}{\multicolumn{4}{|c|}{ Summary Category }} & \multicolumn{3}{|c|}{ Main Events Category } & \multicolumn{2}{|c|}{ Relevance 2} \\
\hline & & & & & \multirow{3}{*}{$\begin{array}{l}\text { Quotation } \\
\text { Sc. } \\
\text { SA }\end{array}$} & \multicolumn{2}{|c|}{ Reported Speech } & \multirow[b]{3}{*}{$\mathrm{T}$} & \multirow[b]{3}{*}{$\mathrm{P}$} \\
\hline & \multicolumn{2}{|c|}{ Headline } & \multicolumn{2}{|c|}{ Lead } & & RV & $\mathrm{RC}$ & & \\
\hline & $\mathrm{S}$ & $\mathrm{C}$ & $\mathrm{T}$ & $\mathrm{P}$ & & $\mathrm{V}$ & SA & & \\
\hline \multirow[t]{6}{*}{ Football } & & $\bullet$ & & $\bullet$ & - & Said & Statement & & $\bullet$ \\
\hline & & & & & & Added & Affirmation & & \\
\hline & & & & & & Said & Statement & & \\
\hline & & & & & & & Affirmation & & \\
\hline & & & & & & & Statement & & \\
\hline & & & & & & & Expectation & & \\
\hline \multirow[t]{3}{*}{ Tennis } & & $\bullet$ & & $\bullet$ & & Said & Statement & & $\bullet$ \\
\hline & & & & & & Said & Statement & & \\
\hline & & & & & & Says & Statement & & \\
\hline \multirow[t]{6}{*}{ Formula 1} & & $\bullet$ & & - & & Said & Statement & & - \\
\hline & & & & & & Said & Affirmation & & \\
\hline & & & & & & Said & Assertion & & \\
\hline & & & & & & & Affirmation & & \\
\hline & & & & & & & Statement & & \\
\hline & & & & & & Told & Affirmation & & \\
\hline \multirow[t]{2}{*}{ Golf } & $\bullet$ & & & $\bullet$ & & Said & Statement & & $\bullet$ \\
\hline & & & & & & Added & Expressing boosting & & \\
\hline
\end{tabular}

Note. $S=$ summary, $C=$ connotative, $T=$ topical, $P=$ probative, $S c .=$ scare, $R V=$ reporting verb, $R C=$ reported content, $S A=$ speech act, $V=$ verb. 


\section{Results}

After pragmatically analyzing the data under investigation, the results yielded are statistically calculated by means of the percentage equation. This can be explained as follows: the percentages of each type of sports are calculated separately, and then a comparison is made between the various categories of the different games so that conclusions are adequately drawn. Table (2) below exhibits the percentages of all the categories of the developed model (for the occurrences of each category, however, see Appendix A):

Table 2. Percentages of the findings of the analysis of the various categories

\begin{tabular}{|c|c|c|c|c|c|c|c|c|c|c|c|c|c|}
\hline \multirow{2}{*}{$\begin{array}{l}\text { Type of } \\
\text { Sports }\end{array}$} & \multirow[t]{2}{*}{$\mathbf{S}$} & \multirow[t]{2}{*}{ C } & \multirow[t]{2}{*}{$\mathbf{T}$} & \multirow[t]{2}{*}{$\mathbf{P}$} & \multirow{2}{*}{$\begin{array}{c}\text { Say } \\
\text { (said) }\end{array}$} & \multirow[t]{2}{*}{ Told } & \multirow[t]{2}{*}{ Other } & \multirow[t]{2}{*}{ Statement } & \multirow[t]{2}{*}{ Assertion } & \multirow[t]{2}{*}{ Affirmation } & \multirow[t]{2}{*}{ Other } & \multicolumn{2}{|c|}{ Relevance2 } \\
\hline & & & & & & & & & & & & $T$ & $\mathrm{P}$ \\
\hline Football & 0 & $100 \%$ & 0 & $100 \%$ & $50 \%$ & $16.66 \%$ & $33.33 \%$ & $50 \%$ & $20 \%$ & $20 \%$ & $10 \%$ & $50 \%$ & $50 \%$ \\
\hline Tennis & $50 \%$ & $50 \%$ & 0 & $100 \%$ & $100 \%$ & 0 & 0 & $77.77 \%$ & $11.11 \%$ & $11.11 \%$ & 0 & 0 & $100 \%$ \\
\hline Formula1 & $50 \%$ & $50 \%$ & 0 & $100 \%$ & $63.63 \%$ & $18.18 \%$ & $18.18 \%$ & $47.05 \%$ & $5.88 \%$ & $29.41 \%$ & $7.64 \%$ & 0 & $100 \%$ \\
\hline Golf & $100 \%$ & 0 & 0 & $100 \%$ & $50 \%$ & 0 & $50 \%$ & $80 \%$ & 0 & $20 \%$ & 0 & 0 & $100 \%$ \\
\hline
\end{tabular}

Note. $\mathrm{S}=$ summary, $\mathrm{C}=$ connotative, $\mathrm{T}=$ topical, $\mathrm{P}=$ probative.

The results recorded on this Table lead to drawing a number of conclusions the listing of which is the main concern of the following section.

\section{Discussion}

\subsection{Summary Category}

\subsubsection{Headline}

The percentages show that football and golf exhibit a different kind of headline from both tennis and formula1. Football hinges totally upon connotative headlines (as the $100 \%$ proves), whereas golf hinges wholly upon summary headline (with its 100\%). Tennis and formula1, by contrast, record an equal employment of both types of headline with $50 \%$ for each, thus they are alike in this regard.

\subsubsection{Lead}

The four types of sports have in common the same lead, that is, one which is probatively related to the headline (regardless of the type of headline per se). This is supported by the $100 \%$ which they all show. The justification behind such employment is that the probative link between the headline and lead strengthens the report as a whole, considering it the milestone on which everything is built later on.

\subsection{Main Events Category}

\subsubsection{Scare Quotations}

There are no scare quotations found in the data under analysis, so no percentage is recorded in this component.

\subsubsection{Reported Speech}

\subsubsection{Reporting Verb}

The four games reflect the reporter's neutral standpoint owing to the use of "say" more than any other verb. This is proved by the highest percentage which this verb has $(50 \%, 100 \%, 63.3 \%$ and $50 \%$, respectively).

\subsubsection{Reported Content}

This is mainly instantiated by the speech act of statement which records the highest percentage, among others, in all the games analyzed (i.e., $50 \%, 77.77 \%, 47.05 \%$ and $80 \%$, respectively).

\subsection{Relevance 2}

Except for football, probative relevance is the prevailing type which links between the two main categories constituting any sorts news reports as analyzed in this work. This is manifested by the $100 \%$ which all of the last three types list. Nevertheless, football gives an equal percentage distributed between topical and probative linking types, with $50 \%$ for each. It can be stated that, generally speaking, the two categories in such reports are probatively related so that they appear as persuasive and coherent as required.

All these results, in fact, demonstrate that there is no major difference in the employment of the various strategies of their pragmatic structure. Thus, the hypothesis proposed in this paper is rejected. 


\section{Conclusions}

Resting on the results cited above, the following are remarked:

1). Football and golf news reports show a complete tendency towards employing the connotative headline, whereas tennis and formulal news reports incline to utilize both types of headline. This means that there is no guarantee on the type of headline employed; it is a matter of personal choice.

2). Probative relevance is the prevailing type of relevance which binds between the headline and lead. This indicates the interrelatedness between the two parts in which one paves the way to the other. Besides, it connotes that the type of headline has zero influence on the type of relevance employed.

3). Generally speaking, say (or said) is the dominant reporting verb in all the types of sports analyzed. This pinpoints the impartiality of sports news reporters in reporting various events.

4). Roughly speaking, statement is the principal speech act used in the reported content. This also pertains to the impartiality of reporters just mentioned.

5). Probative relevance, in general, is the prevailing type of relevance which ties the two main categories of a sports news report: summary category and main events category.

6). Tennis news reports tolerate little latitude for quotations owing to the nature of the game itself.

7). There are no major differences between the analyzed games as to utilizing the various strategies compiling the developed model. This denotes that there is no relation between the type of the game and the employment of various strategies.

8). Sports news reports, in general, are not mainly concerned with the implied meaning. This is so because the type of events they deal with as well the purpose behind them are not meant for connoting; they just aspire for reporting the events in an impartial way, so to speak.

9). The developed model has proved its accuracy and suitability for analyzing sports news reports.

\section{References}

Agu, I. (2015). A Linguistic- Stylistic Analysis of Newspaper Reportage. International Journal of Research in Humanities and Social Studies, 2(8), 20-27. Sryahwa Publications.

Bell, A. (1991). The Language of News Media. Oxford: Blackwell.

Dijk, V. (1988). News as Discourse. New Jersey: Lawrence Erlbaum Associates Publishers.

Dijk, V. (1988b). News Analysis: Case Studies of International and National News in the Press. New Jersey: Lawrence Erlbaum Associates Publishers.

http://www.bbc.com/sport/football/38019070

http://www.bbc.com/sport/football/38054150

http://www.bbc.com/sport/formula1/38131703

http://www.bbc.com/sport/formula1/39234387

http://www.bbc.com/sport/golf/38046531

http://www.bbc.com/sport/golf/38056670

http://www.bbc.com/sport/tennis/37665915

http://www.bbc.com/sport/tennis/37882468

https://dinfos.blackboard.com/bbcswebdav/library/Library\%20Content/Public\%20Affairs\%20-\%20PALD/Eleme nts\%20of\%20News.pdf

Leech, G. (1974). Semantics. England: Penguin Books.

Mustafa, S. (2010). The Interpretation of implicature: A Comparative Study between Implicature in Linguistics and Journalism. Journal of Language Teaching and Research, 1(1), 35-43. Academy Publishers.

Pajunen, J. (2008). Linguistic Analysis of Newspaper Discourse in Theory and Practice. Unpublished M.A. Thesis. University of Tampere.

Sunday, O., Belmolokwu, J., \& Onwubere, C. (2012). Introduction to News Reporting and Writing. National Open University of Nigeria.

Walton, D. (1995). A Pragmatic Study of Fallacy. Alabama: University of Alabama Press. 
Walton, D. (2006). Fundamentals of Critical Argumentation. Cambridge: Cambridge University Press.

Wilson, D., \& Sperber, D. (2004). Relevance Theory. In L. Horn \& G. Ward (Eds.), The Handbook of Pragmatics (pp. 607-632). Oxford: Blackwell. https://doi.org/10.4304/jltr.1.1.35-43

\section{Appendix A}

\section{Occurrences of the Different Strategies of the Model}

\begin{tabular}{|c|c|c|c|c|c|c|c|c|c|c|c|c|c|}
\hline Sport & $\mathrm{S}$ & $\mathrm{C}$ & $\mathrm{T}$ & $\mathrm{P}$ & Say (said) & Told & Other & Statement & Affirmation & Assertion & Other & $\mathrm{T} 2$ & $\mathrm{P} 2$ \\
\hline$F$ & 0 & 2 & 0 & 2 & 3 & 1 & 2 & 5 & 2 & 2 & 1 & 1 & 1 \\
\hline Te. & 1 & 1 & 0 & 2 & 6 & 0 & 0 & 7 & 1 & 1 & 0 & 0 & 2 \\
\hline Fo. & 1 & 1 & 0 & 2 & 7 & 2 & 2 & 8 & 5 & 1 & 3 & 0 & 2 \\
\hline G. & 2 & 0 & 0 & 2 & 2 & 0 & 2 & 4 & 0 & 0 & 1 & 0 & 2 \\
\hline
\end{tabular}

Note. $\mathrm{S}=$ summary, $\mathrm{C}=$ connotative, $\mathrm{T}(2)=$ topical, $\mathrm{P}(2)=$ probative, $\mathrm{F} .=$ football, $\mathrm{Te} .=$ tennis, Fo. $=$ formula1, $\mathrm{G} .=$ golf.

\section{Copyrights}

Copyright for this article is retained by the author(s), with first publication rights granted to the journal.

This is an open-access article distributed under the terms and conditions of the Creative Commons Attribution license (http://creativecommons.org/licenses/by/4.0/). 